Traducción visual. Epistemología de la traducción en las artes visuales Modesta Di Paola

\title{
TRADUCCIÓN VISUAL EPISTEMOLOGÍA DE LA TRADUCCIÓN EN LAS ARTES VISUALES
}

\author{
VISUAL TRANSLATION \\ EPISTEMOLOGY OF TRANSLATION IN VISUAL ARTS
}

\author{
Modesta Di Paola \\ mdipaola@ucm.es
}

Facultad de Geografía e Historia

Universidad Complutense de Madrid. España

Recibido: 23/12/2017

Aceptado: 17/3/2018

\section{RESUMEN}

El interés hacia la traducción, desde una perspectiva transcultural y global, ha desarrollado nuevas aproximaciones teóricas alrededor de los artefactos artísticos nacidos en contextos transculturales debido, sobre todo, a la disolución de las fronteras entre varios ámbitos disciplinares y las historias del arte. La traducción ha sido articulada como un concepto hermenéutico para entender la complejidad de los artefactos artísticos en los que coexisten la imagen y el texto. Sin embargo, dentro de la teoría crítica nunca se ha desarrollado una investigación dirigida a identificar el status quoestionis de una larga pero denegada alianza entre el arte y la traducción. Este artículo perfila algunas de las teorías críticas y de las prácticas artísticas contemporáneas que usan la traducción visual en los procesos de transmisión y de recepción de las obras de arte contemporáneo.

\section{Palabras clave}

Traducción visual; texto/imagen; transculturalidad; intermedialidad; globalización

\section{ABSTRACT}

The interest in translation, from a transcultural and global perspective, has brought about new approaches to historical artefacts in art theory research, leading to an ever-increasing dissolution of boundaries between the various fields of art history. Nevertheless, the concept of translation has been articulated as a hermeneutical means to understand the complexity of contemporary works of art in which text and image coexist. Yet within critic theory there has never been a concrete research work with the purpose of identifying the status quaestionis of a long-time neglected but crucial topic: visual translation. This article involves critical theories and contemporary artistic practices that use the concept visual translation in the process of transmission and reception of contemporary art.

\section{KEYWORDS}

Visual translation; text/image; transculturality; intermediality; globalization 
Tradicionalmente, la palabra traducción ha sido designada para describir una determinada práctica literaria: en el sentido estricto representa la acción de trasladar un texto de una lengua a otra. Sin embargo, la traducción es polisémica y tiene multitud de significados adyacentes. A partir de su análisis etimológico (del latín traducére, pasar de un lado a otro, compuesto por el prefijo trons- de un lado a otro y ducere- guiar, dirigir), el término justifica muchas posibilidades interpretativas. En la acepción amplia, la traducción se refiere al acto de traslación, de transferir, de trasladar, de traicionar y de la metáfora, por tanto su valor implícito caracteriza no solo la traslación de una lengua a otra, sino también el acto de transformar, de interpretar y de recrear. Sin embargo, solo recientemente la sinonimia de la traducción se ha asociado a otras disciplinas debido, principalmente, al giro cultural (cultural turn) promulgado por los teóricos Susan Bassnett y André Lefevere (1990) en los Translation Studies, una interdisciplina de matriz anglosajona que desde los años noventa ha ido relacionando cada vez más la traducción con otros ámbitos, como los estudios poscoloniales, los estudios de la diáspora, los Border Studies y los Gender Studies. Para los dos autores, la cultura entendida como un proceso dinámico que implica diferencias y colisiones requiere de constantes procesos de negociación. En este sentido, la traducción constituye el paradigma de cualquier mediación, no solo entre las lenguas, sino también entre las culturas. Gracias a este paradigma la traducción ha sido también objeto de interés en diversos sectores del arte contemporáneo, sobre todo a la hora de interpretar artefactos artísticos producidos en el seno de un contexto transnacional e intercultural.

El interés hacia las transferencias de significados en varios contextos del conocimiento humano ha comportado la realización de algunas conferencias y seminarios en todo el mundo. Durante el Congreso Internacional Art in Tronslation, organizado en Reykjavik (Islandia) en 2012, se desarrollaron una serie de preguntas acerca del problema de la traducción en el ámbito artístico: ¿cómo pueden ser transnacionales y/o nacionales las lenguas localizadas que se adaptan a los discursos del arte globalizado? ¿Cómo las comunidades de lenguas sin una larga tradición de historia del arte o discursos teóricos artísticos adoptan, traducen y codifican términos extranjeros o conceptos que nunca habían conocido? ¿Cuáles son las consecuencias (positivas o negativas) para los artistas que utilizan una segunda o una tercera lengua en sus creaciones?

Como resulta evidente, los temas principales se plantearon desde el propio ámbito de la lingüística. Es bastante sintomático que la relación entre arte y traducción se mueva en un contexto predominante de tipo lingüístico, lo que refuerza la idea de que la traducción aplicada al campo de la teoría del arte debe tener enfoques literarios y comparativos. Testimonio de esta actitud son las innumerables exposiciones de arte internacionales organizadas bajo el denominador común troducción: Translaziuns Paradoxien Malenclegïentschas, en Zúrich (2008); Bad Translation, llevada a cabo en el Crate Studio and Project Space de Margate (2009-2010); Translation is a mode, en el Kunstraum Niederoesterreich de Viena (2010); Found in Tronslation realizada en el Museo Guggenheim de Nueva York (2011); The Spiral and the Square. Exercises on Translatability, en la Bonniers Konsthall de Estocolmo (2011). Aunque el tema principal sea la relación que el arte establece con la traducción, el valor conceptual dominante de estos eventos se desarrolla desde una aproximación de tipo lingüística, literaria y metafórica sobre la condición transcultural del arte global contemporáneo.

¿Sería posible hablar de una epistemología de la traducción visual que se desarrolle en y desde el ámbito propiamente artístico y visual? En el presente artículo se crean las premisas teóricas para establecer una alianza conceptual entre la traducción cultural y las artes visuales, demostrando que esta alianza se entrecruza no solo con diferentes tradiciones históricas y geográficas, sino también con la teoría de la imagen que actualmente ocupa el lugar central de los debates internacionales nacidos dentro de la Bildwissenschaft (cultura visual) de área germanófona, los Visual Studies y Visual Culture Studies de área angloamericana y latinoamericana, la tradición francesa de historia y teoría del arte y la semiótica de la imagen de ámbito italiano. Se trata de un vasto horizonte de estudios que indaga las dinámicas de la cultura visual, situando su interés no solo en una posición teórico-ontológica, sino más bien en la práctica de la imagen, en su circulación, en la estratificación temporal y de la memoria en el universo cultural. En este amplio contexto, la cuestión de la relación entre las artes, la traducibilidad de un lenguaje visual a otro, las formas o las sustancias de la expresión en otros ámbitos de producción, la inminencia propia de una imagen, la migración y la permanencia de significados en la producción de las obras de arte, son solo algunos de los problemas que se plantea una posible epistemología de la traducción visual. 
Por su complejidad conceptual y práctica, la teoría de la traducción visual se sitúa en el espacio móvil y descentralizado de la interdisciplinariedad desde el cual se despliegan tres posibles zonas conceptuales que relacionan la teoría de la imagen, la práctica artística y la traducción. La primera es la traducción lingüística, sobre todo, la que forma la base para una epistemología histórica y crítica de la traducción como metáfora de la relación entre las artes. La segunda, y complementaria a la primera, concierne a la teoría sobre traducción intermedial (intermedial translation) surgida como consecuencia del cruce entre ámbitos disciplinares (crossing boundaries) y realidades mediales y culturales. La tercera es la teoría sobre traducción transcultural que analiza el discurso sobre la globalización y, consecuentemente, la necesidad ontológica de un diálogo intercultural y transnacional. En este ámbito, la traducción se revela como la metáfora más apropiada para las prácticas artísticas interculturales y transnacionales. Por lo tanto, el estudio de la pluralidad y la articulación entre identidad y alteridad, entre lo uno y lo diverso, resulta fundamental. Al abordar el análisis de la interculturalidad y de la dialéctica entre la alienación y la asimilación que subyace a todo intercambio cultural, surge la necesidad de una teoría acerca de la traducibilidad cultural en las artes visuales.

\section{LA TRADUCCIÓN COMO METÁFORA}

Las más recientes investigaciones de los Estudios Visuales han subrayado que la relación entre el arte visual y la literatura se mueve en un terreno híbrido constituido por préstamos y por transferencias de términos y de conceptos. Esta actitud de asimilar un vocabulario de términos desde un ámbito de estudio hacia otro, lejos de ser un intento de suplir cierta falta de imaginación, representa una de las características más importantes y complejas del debate contemporáneo sobre la naturaleza de la imagen y su poder de comunicar a nivel lingüístico, cultural, metafórico y simbólico. En la mayoría de los casos, la imagen ha sido considerada como una representación de un mensaje de tipo lingüístico-simbólico que tiene que ser comprendido e interpretado. La copacidad comunicativa de la imagen (verbal o escrita, mental o pictórica) ha despertado el interés tanto de poetas, lingüistas y literatos como de artistas y críticos del arte.

El fenómeno de la migración de términos, desde siempre presente en la historia de las ciencias humanas, se ha caracterizado recientemente por una predominancia de la componente icónica en el debate que ve la imagen y el texto (eikon y logos) como principios fundamentales de la capacidad humana de imaginar y de representar la realidad. Actualmente, la teoría del arte, la crítica literaria y los estudios visuales conducen investigaciones sistemáticas y, a menudo, entre-cruzados acerca del fenómeno interartístico y de la imagen/texto -ambos consecuencia del giro icónico y de la teoría de la imagen elaboradas respectivamente por Gottfried Boehm (1994) y por William J. Thomas Mitchell (2009) - para explicar y entender la carga comunicativa, lingüística y cultural de las imágenes.

Según el historiador del arte y filósofo alemán Boehm, la imagen (es decir, lo que es figurativo y pictórico) constituye un elemento esencial del lenguaje. El mecanismo fundamental que permite el funcionamiento icónico del lenguaje es la metáfora, una figura estilística literaria muy frecuente en nuestro habla cotidiana (Boehm, 1994). La metáfora tiene un aspecto figurativo y un color estilístico que para Boehm determina la iconicidad del lenguaje. Mitchell elabora una teoría de la imagen que, tomando distancia de la Iconología tradicional, intenta definir una iconología literario en la que el fenómeno visual está vinculado de forma directa a la interconexión entre palabra e imagen. Ambos teóricos, desde enfoques diferentes, reconocen que el lenguaje es un instrumento lingüístico para la comprensión, pero también un conglomerado de metáforas y de comparaciones figurativas que usamos en la comunicación verbal y escrita. El lenguaje se proyecta en la mente como una secuencia de imágenes ya conocidas anteriormente, así que cuando Boehm en su iconic turn (giro icónico) ${ }^{1}$ y Mitchell en su pictorial turn (giro pictorial)² hablan de metáfora, reconocen su esencia figurativa.

\footnotetext{
1 En 1994 el teórico alemán Gottfried Boehm formula un giro icónico (iconic turn) con la intención de integrar la imagen (eikon) y la palabra (logos) en un mismo modelo interpretativo a partir de la idea de que el ser humano puede definirse solo por medio de y en relación con las imágenes.

2 En los años noventa, Mitchell postula dentro del ámbito de los Estudios Visuales el giro pictorial para reflexionar acerca de las interconexiones entre el arte, los nuevos medios, las tecnologías y la cultura.
} 
A partir de estas posiciones teóricas, se podría elaborar un discurso acerca de la metoforicidad de las imágenes de este tipo: la imagen contiene un mensaje lingüístico que debe ser descifrado y entendido, en cuanto el lenguaje es parte esencial de las imágenes y la imagen es parte esencial de la comunicación lingüística. Como consecuencia de esta esencialidad, términos comúnmente aplicados al campo de la lingüística y de la literatura pueden migrar hacia el ámbito visual y viceversa. Este cruce disciplinario se debe esencialmente a la naturaleza troslativa de las palabras. No sorprende que la misma palabra metófora (del griego metopherein: formada de meto, fuera o más allá, y pherein, trasladar) comparta su espacio semántico con traducción.

La idea de movimiento, de trasferencia, de cruzar bordes conceptuales y disciplinares es lo que tienen en común la traducción y la metaforicidad del lenguaje. Así que la traducción, como la metáfora, incluye y abraza ámbitos de estudios autónomos pero relacionados y permite reflexionar sobre la transposición de significados desde la percepción hasta la conceptualización de la imagen, del fenómeno interartístico, ${ }^{3}$ de la relación entre la imagen y el texto y acerca de la migración de los términos y conceptos. Si la metáfora es el tropo por excelencia, porque traslada el significado de una palabra a otra; la traducción visual es la metáfora de una traslación que va desde la palabra, el mensaje y la narración hasta la imagen. Este proceso pertenece, en realidad, a la misma naturaleza representativa de la imagen en cuanto la traducción se conforma como una esencia metafórica por todo acto de traslación, de traslado y de transferencia lingüística en la imagen.

En un artículo, de 2006, Mike Bal señala que los conceptos no están fijos, sino que viajan entre disciplinas, entre investigadores, entre periodos históricos y entre comunidades geográficamente dispersas. La relación entre la literatura y el arte visual es transversal a muchos ámbitos de estudio y, por tanto, ha sido posible que viejos conceptos hayan generado nuevos criterios de interpretación respecto del objeto interartístico. Moviéndose entre conceptos, muchos teóricos han llegado a identificar los mismos recursos retóricos, figuras del habla y tropos (la metáfora visual, la hipérbole, la sinécdoque, la metonimia, etcétera) tanto en la comunicación verbal como en la imagen. A partir del ámbito de la comparación literaria, pasando por la semiótica hasta los estudios contemporáneos acerca de la mirada, la tendencia general ha sido la de intentar encontrar similitudes conceptuales entre el icono y el logos. Desde este punto de vista, uno de los más fascinantes desplazamientos conceptuales que se han producido en las disciplinas humanísticas es la relación entre las artes hermanas. Desde la antigüedad, las artes hermanas han relacionado sus intereses interartísticos por medio de préstamos y de coincidencias conceptuales. La traducción como metáfora se ha evidenciado en los procesos de transformación, recreación, reescritura de un medio a otro y por siglos ha dominado la alianza entre las artes visuales, la música y la poesía. Demostración de esta relación han sido las afortunadas fórmulas clásicas del ut pictura poěsis, del pictŭra muto poěsis y de las antiguas praxis de la écfrasis, así como las conexiones que la pintura ha ido estrechando con muchos tropos de la retórica clásica y moderna. La metáfora de la traducción se ha detectado en el campo de análisis de la retórica visual, sobre todo, de Roland Barthes (2005) y de Umberto Eco (1989) (este último, por ejemplo, habla de figuros traslativas) y en la práctica de la écfrasis contemporánea elaborada por Jean Hagstrum (1958), Wendy Steiner (1982), Murray Krieger (1991), etcétera. Sin embargo, es con los estudios de iconología crítica desarrollados por Mitchell (2009), que el discurso sobre traducción lingüística y cultural en las artes se fortifica, sobre todo, con referencia a la interpretación de la imagen/texto.

\section{LA TRADUCCIÓN INTERMEDIAL}

El concepto de traducción se desarrolla en varios niveles de comprensión de las complejas dinámicas que regulan las relaciones humanas. Sin embargo, dos son los intereses principales en la formulación de una teoría de la traducción visual: la traducción entre los lenguas y la traducción entre lenguajes artísticos. Aunque en ambas se muestran constantes sinergias conceptuales, la primera se enfoca en el sentido literario y filosófico de los intercambios lingüísticos, mientras que la segunda se centra en la traducción como elemento metafórico para meditar acerca de algunas formas intermediales en las que los lenguajes y los medios tecnológicos de comunicación operan a través de la palabra, la escritura, el sonido y la codificación pictórica. 
Esta interrelación es evidente, por ejemplo, en el lenguaje audiovisual y en la performance, ambas prácticas artísticas que han provocado la desarticulación de los confines disciplinares, uniendo las clásicas tipologías de la visualidad con formas literarias como el cuento, la poesía, la crónica, las memorias o las relaciones de viaje, la documentación del extraño, la alteridad y, en general, los fenómenos que testifican la experiencia personal e intercultural. Cuestiones relativas a la traducción, de hecho, se han podido integrar al arte visual, por un lado, como herramienta indispensable para interpretar obras de arte producidas en diferentes contextos geográficos o culturales; por otro, como elemento formal indispensable para la realización de artefactos artísticos que, a su vez, quieren interpretar diferentes realidades artísticas, sociales, antropológicas o políticas. Aquí, el concepto de cultura de masas es fundamental para entender el proceso de redefinición de la imagen, la imagen/texto, la obra de arte y, en general, las artes visuales.

A partir de los años setenta, los estudios sociales han hecho hincapié en la elaboración de nuevas definiciones semióticas acerca del concepto de cultura. Esta elaboración se movía alrededor de una valoración crítica sobre la cultura subalterna en contraposición a la cultura hegemónica. Se trataba de cambiar el registro de la cultura dominante y de incluir un lenguaje crítico capaz de repensar los valores de la modernidad. Las minorías, el subalterno y el excluido se volvieron los temas centrales para reflexionar acerca de los roles dominantes y occidentales, así como para la reelaboración radical del sentido complejo de la pertenencia a una historia diversificada. De la misma forma, el análisis de la imagen se abrió a la crítica de las formas del arte hegemónico. Los análisis de la subcultura en los años setenta, la crítica a la moral conformista de los años ochenta, la lucha y el activismo de los inmigrantes negros, la reconfiguración del feminismo crítico, los estudios sobre los géneros sexuales y las identidades étnicas han vuelto a configurar las políticas sociales y culturales y ha aumentado la producción teórica alrededor de estos temas. Como los estudios de la cultura visual, la producción artística no se ha mostrado indiferente a estas cuestiones sociales y culturales. Más bien, ha subrayado su vivo interés apoyando cada una de las causas políticas y sociales que entre los años setenta y nuestros días han cambiado la manera de entender el fenómeno visual. La interpretación de la imagen y su comprensión se han convertido en las herramientas de estudio y de análisis de la cultura visual. Los estudios visuales han puesto en marcha una reflexión acerca de la imogen como lenguaje, con su propio sistema semiótico y su compleja simbología. En este contexto, se propone una nueva alianza entre el arte y la literatura, manifiesta sobre todo en la combinación de herramientas y de categorías propias del análisis textual literario y el análisis de los textos pictóricos, cinematográficos, fotográficos, etcétera. El denominador común, en todo caso, es la componente cultural. Además, desde el final de los años noventa, las historias del arte contemporáneo han dirigido sus análisis hacia el ámbito cultural aumentando las posibilidades de análisis y de interpretación de las imágenes producidas bajo los fenómenos de la globalización y de la cultura digital.

Estas asonancias han sido detectadas en un monográfico publicado en la revista inglesa Journol of Visual Culture, en 2007. En la introducción, titulada «Acts of Translation», Mieke Bal y Joanne Morra, las editoras de este número, describen la traducción como un concepto crucial en las discusiones internacionales sobre las prácticas visuales y culturales. La segunda parte termina con la descripción de la traducción como el detonante para las reflexiones sobre arte por parte de teóricos, como Emily Apter, Lawrence Venuti, Gary Shapiro, Nora Alter, Sonja Neef y la misma Bal. La traducción y la visión, dos prácticas aparentemente distintas, la primera comúnmente circunscrita a la práctica literaria y la segunda específica de la historia del arte, comparten evidentes zonas teóricas como las que más o menos explícitamente analizan los discursos sobre la diáspora, la identidad o la construcción del otro, puntos de contacto estos que se hallan en los lugares de la traducción cultural y de las prácticas artísticas contemporáneas que investigan los discursos sobre globalización, la internacionalización del sistema literario y artístico, y la necesidad de establecer un diálogo intercultural e internacional entre diferentes agentes del mundo artístico y cultural contemporáneo.

Esta problemática se hace patente en otro artículo de Bal (2007) en el que la globalización se describe como un acontecimiento que tiene sus raíces en las estructuras del colonialismo y que reverbera con sus ecos hasta nuestros días. El fenómeno de la globalización se extiende en un territorio desconocido, borrando la identidad cultural y los centros culturales fijos. Así, Bal describe el concepto de migratory aesthetics (estética migratoria) como el fenómeno que relaciona la experiencia estética con la migración, entendida bien como migración de sujetos y de cosas en el espacio, bien como movimiento intelectual y cultural. La autora reflexiona, sobre todo, sobre 
los problemas que relacionan las prácticas artísticas (cuyas procedencias ya no pueden ser taxonómicamente identificadas debido a la globalización) ligadas a las nuevas tecnologías, como el videoarte. Sus análisis de la globalización y la visualidad se detienen en el video que la misma teórica ha realizado, Perdidos en el espacio (Bal \& Entekhabi, 2005) cuyo eje principal es el desplazamiento y la dislocación como consecuencia de la migración. El medio dominante del video es la voz humana de un iraní llamado Daryush. Su dificultad para hablar inglés se visualiza no solo en el lenguaje y en el acento, sino también en su misma expresión física y, por tanto, en la gestualidad que adopta. La inquietud de hablar inglés desentraña por medio de un acento forzado lo que está oculto en el fondo, es decir el sentimiento que se genera al desplazarse. El mismo Daryush confiesa que «lo que más echaba de menos era hablar su propio idioma» (Daryush en Bal, 2007, p. 27), el lenguaje que le es propio, la lengua de su casa. El sentimiento de obligación a traducirse a sí mismo para comunicarse con el otro (sentimiento que en muchos casos domina al sujeto diaspórico) genera apuro y tensión, debido, sobre todo, a la resistencia que cada migrante experimenta hacia el nuevo idioma, la cultura local y los valores sociales y políticos con los cuales no consigue identificarse.

\section{LA TRADUCCIÓN EN CONTEXTOS TRANSCULTURALES}

Al incrementarse el interés por el fenómeno de la globalización, el análisis del concepto de traducción se ha consolidado dentro de los departamentos de estudios culturales. En estas últimas décadas, críticos literarios, historiadores del arte y teóricos de la imagen han empezado a usar la metáfora de la traducción para crear nuevas tramas interpretativas de la imagen/texto a partir de conceptos como local y global, colonizado y colonizador, original y copia, pureza e hibridismo. Estas teorías, en algunos casos sumergidas en el posestructuralismo, aunque con desigual énfasis, han plasmado una crítica de la resistencia en contra del proyecto etnocéntrico. La importancia de la traducción como transferencia intercultural se ha comprobado a partir de las Trovelling Theories, sobre todo las desarrolladas por Maria L. Pratt (1992), en su teoría del contoct zone; por Emily Apter (2005), en la elaboración de una nueva literatura comparativa en la que la traducción se manifiesta como zono de guerra y de conflicto; y por el concepto de viaje como traducción, desarrollado por James Clifford (1997). En este contexto interdisciplinar se han podido analizar una serie de conceptos relevantes para una nueva interpretación de la traducción entendida como mediación en contextos transnacionales. André Lefevere (1992) es quien pensó en el término reescribir, que en algunos casos nos evitaría distinguir entre las varias formas de la reescritura, como la traducción, la adaptación y la emulación. Traducción como recreación o como transcreación es una definición que deriva de la escuela brasileña de traducción dirigida por los hermanos Haroldo y Augusto de Campos, fundadores de la poesía visual brasileña. Para ellos, recreor es la posibilidad de traducir creativamente y, por lo tanto, de realizar una traducción-arte (Süssekind \& Castañon Guimarães, 2004). En este ámbito, el arte visual y la literatura encuentran su punto de intersección. La misma poesía concreta es una poesía que desarrolla la potencialidad visual de las letras, creando imágenes de gran valor estético. En estos contextos conceptuales, la traducción se rige como elemento de mediación y de comprensión entre diferentes dinámicas interculturales. El in between, el entremedio fronterizo, diaspórico e híbrido es lo que lleva a otras conceptualizaciones acerca de la traducción: alteridad (Bhabha, 1994), inbetweeness (Lotbinière-Harwood, 1991) y subalternidad (Spivak, 2000), frontera (Anzaldúa, 1987), hibridismo (García Canclini, 1997), criollización (Glissant, 1995), viaje, inmigración y nomadismo son términos nacidos dentro de los Translation Studies, los estudios postcoloniales, los Border Studies y los Gender Studies; conceptos que han permitido analizar también la producción artística contemporánea bajo otros enfoques disciplinares a través de una mediación indispensable entre las culturas, aunque no siempre ajena a manipulaciones de poder.

\section{CONCLUSIONES. ON TRANSLATION, DE ANTONI MUNTADAS}

La obra de Antoni Muntadas es seguramente el caso más importante de traducción lingüística, cultural e intercultural en las artes visuales. La serie de trabajos artísticos titulada On Trans/ation apareció por primera vez en 1995 y desde entonces el artista ha investigado la propia traducción como fenómeno visual en relación con lo global, lo glocal, lo transnacional, lo intercultural y lo intermedial. A partir de su trabajo se puede elaborar una teoría crítica en torno a la idea de que la traducción visual es un acto complejo que se vincula a las diferentes manifestaciones de la creatividad humana, no solo dentro del ámbito puramente literario, sino también dentro de las artes visuales que, en el caso 
de Muntadas, se halla principalmente en el lenguaje verbal o escrito con sus códigos lingüísticos y semánticos (el proyecto Worning, por ejemplo, se desarrolla a partir de una búsqueda semántica). Junto con el significado de las palabras, hay que añadir la importancia de la investigación semiológica que el artista desarrolla al relacionar las imágenes con las palabras y los conceptos. En esta línea, la obra se analiza bajo la luz de la retórica visual en cuanto que ha transformado el significado de estilo que representa tanto el aspecto estético de un artefacto artístico como la estrategia de comunicación para la transmisión de mensajes e informaciones (Di Paola, 2017). La retórica, con sus tropos y sus figuras, es solo una de las prácticas utilizada por Muntadas para expresar el significado y el significante en sus obras. Los ámbitos de la literatura y de la lingüística juegan un papel fundamental en la creación de su trabajo: la composición, el contenido simbólico, el tipo de fuente, la lectura son herramientas básicas del lenguaje adoptado por el artista en la definición de todos sus proyectos. La transposición de los conceptos de la literatura en el campo del arte es pues otro tema de reflexión que nos acerca a la traducción en sus proyectos. La producción artística de Muntadas se presenta, por tanto, como el ejemplo más completo y complejo para desarrollar una reflexión acerca de la traducción visual. La producción artística de Muntadas ha favorecido el interés de la teoría del arte hacia la traducción aún más si consideramos la progresiva incorporación de este concepto en su producción artística. Aquí la traducción se juega en varios niveles de comprensión de las dinámicas que regulan las relaciones humanas. Si entendemos por obro de orte un artefacto complejo realizado con diferentes medios que determinan su forma y, por tanto, su estilo y en el que cohabitan diferentes narrativas culturales que se mueven entre la alteridad y la diáspora y en contextos transculturales, entonces, la traducción visual nos abre la posibilidad de descifrar los mensajes artísticos y las representaciones formales bajo nuevos enfoques.

Artistas de varios ámbitos culturales y geográficos han usado de forma directa el concepto de traducción en su producción, estableciendo los parámetros de una posible aplicación del concepto de traducción intercultural en el arte visual. La experiencia nómada de la obra de arte en el sistema internacional, deambulando sin hogar fijo, más allá de las fronteras, portadora del ser y de la diferencia, ya no es la expresión de una historia o de una tradición singular. Es el reflejo de un pensamiento que vaga sin rumbo fijo, se traslada y, por tanto, requiere ser traducido.

\section{REFERENCIAS}

Anzaldúa, G. (1987). Borderlands / Lo frontero. The New Mestiza. San Francisco, Estados Unidos: Aunt Lute Books.

Apter, E. (2005). The Translation Zone: A New Comparative Literature. Princeton, Estados Unidos: Princeton University Press.

Bal, M. (2006). Conceptos viajeros en las humanidades. Estudios Visuales, (3), 28-77. Recuperado de https://dialnet.unirioja.es/servlet/articulo?codigo=3015783

Bal, M. (2007), Lost in Space, Lost in the Library. En Essays in Migratory Aesthetics. Cultural Practices Between Migration and Art-making (pp. 23-36). Amsterdam, Países Bajos: Rodopi.

Bal, M. y Morra, J. (2007). Acts of Translation. Journal of Visual Culture, 6(1), 5-11. Recuperado de http:// journals.sagepub.com/toc/vcua/6/1

Bal, M. y Entekhabi, S. (Directores). (2005). Lost in Space [Película]. Países Bajos.

Barthes, R. (2005). Rhetoric of the Image. En The Visual Culture Reoder (pp. 33-40). Londres, Inglaterra: Sage.

Bassnett, S. y Lefevere, A. (1990). Translation, History and Culture. Londres, Inglaterra: Pinter.

Bhabha, H. (1994). The Location of Culture. Londres, Inglaterra: Routledge. 
Boehm, G. (1994). Die Wiederkehr der Bilder. En Was ist ein Bild? (pp.11-38). Munich, Alemania: Fink.

Clifford, J. (1997). Routes: Travel and Translation in the Late Twentieth Century. Boston, Estados Unidos: Harvard University Press.

Di Paola, M. (2017). L'arte che traduce. La traduzione visuale nell'opera di Antoni Muntadas. Milan, Italia: Mimesis.

Eco, U. (1989). Lo struttura assente. Milán, Italia: Bompiani.

García Canclini, N. (1997). Cultura y comunicación: entre lo global y lo local. La Plata, Argentina: Facultad de Periodismo y Comunicación Social, Universidad Nacional de La Plata.

Glissant, É. (1995). Introduction ò une poétique du divers. Paris, Francia: Gallimard.

Hagstrum, J. (1958). The Sister Arts. The Tradition of Literary Pictorialism in English Poetry from Dryden to Groy. Chicago, Estados Unidos: University of Chicago Press.

Krieger, M. (1991). Ekphrasis. The Illusion of Natural Sign. Baltimore, Estados Unidos: Johns Hopkins University Press.

Lefevere, A. (1992). Translation, Rewriting, and the Manipulation of Literary Fame. Londres, Inglaterra: Routledge.

Lotbnière-Harwood, S. (1991). Re-belle et infidèle: Lo Traduction comme pratique de réécriture ou féminine/The Body Bilingual: Translation as a Rewriting in the Feminine. Montréal, Canadá: Les éditions du remue-ménage.

Mitchell, W. J. T. (2009). Teoría de la imagen. Madrid, España: Akal.

Pratt, M. L. (1992). Imperial Eyes: Travel Writing and Transculturation. Nueva York, Estados Unidos: Routledge.

Spivak, G. C. (2000). The Politics of Translation. En The Tronslation Studies Reader (pp. 397-416). Londres, Inglaterra: Routledge.

Steiner, W. (1982). The Color of Rhetoric. Chicago, Estados Unidos: The University Chicago Press.

Süssekind, F. y Castañon Guimarães, J. (2004). Sobre Augusto de Compos. Rio de Janeiro, Brasil: 7Letras/ Fundação Casa de Rui Barbosa. 